\title{
A CLINICAL COMPARISON OF DIAZEPAM AND THIOPENTONE AS INDUCTION AGENTS TO GENERAL ANAESTHESIA
}

\author{
G. S. Fox, M.D., F.R.C.P.(c), J. E. WYNANDS, M.D., C.M., AND \\ M. BHAMBHAMI, M.B., B.S. ${ }^{*}$
}

DiazepaM, a benzodiazepine derivative (Fig. 1), has previously been used as a premedicant drug ${ }^{1-3}$ and as an induction agent for general anaesthesia. ${ }^{4}$ Prensky et al. ${ }^{5}$ recently reported on the use of intravenous diazepam as a method of controlling prolonged seizures. The purpose of this investigation was to compare thiopentone and diazepam as induction agents for short operative procedures.<smiles>CCOC(=NCc1ccccc1)c1cc(Cl)ccc1N(C)C</smiles>

Figure 1. Diazepam formula.

\section{METHoD}

Two hundred patients undergoing cystoscopy, with or without retrograde pyelography, were studied. Half of the patients were induced with 2.5 per cent thiopentone intravenously, the remainder with diazepam. Diazepam was diluted in normal saline immediately prior to anaesthesia, and used as a 0.1 per cent solution in 50 patients. The remaining 50 patients were induced with 0.5 per cent diazepam intravenously. On arrival in the operating room, the patients were given atropine $0.4 \mathrm{mg}$. intravenously. No other premedicant drugs were administered, nor were the patients receiving medications for other reasons. When an increase in pulse rate occurred, the patients were induced intravenously with either diazepam or thiopentone. If a rise in pulse rate was not obtained, the patients were induced two minutes after the intravenous injection of the atropine. Maintenance of anaesthesia was with nitrous oxide $(6 \mathrm{~L} . / \mathrm{min}$.) and oxygen ( $3 \mathrm{~L} . / \mathrm{min}$.) through a Magill circuit using a face mask. Halothane was added in sufficient concentration to achieve satisfactory general anaesthesia, and thereafter the patients were maintained in as light a plane as possible. An attempt was made to anticipate the end of surgery and to decrease the concentrations of inhalational

-Department of Anaesthesia, Royal Victoria Hospital, Montreal. 
agents in order that the patients would be as near the awake state as possible at the end of surgery.

Using a sphygmomanometer cuff and auscultation, alterations in blood pressure were recorded following the administration of the induction agent. Alterations in pulse rate were noted. Laryngeal and pharyngeal reflexes were also assessed. Changes in respiratory patterns were observed.

Emergence from anaesthesia was compared in the two groups. Return to a level of anaesthesia which permitted a response to pain was tested by pinching the patient's shoulder. A satisfactory return to consciousness was considered to be achieved when the patient replied to a simple question, e.g. "What is your address?"

Immediately prior to induction of anaesthesia and during emergence the patients were given statements and questions specifically intended for the assessment of pre- and postoperative amnesia. All patients were visited on the wards on the first and second postoperative days. Outpatients were contacted at similar intervals at home or office for follow-up questioning.

The data collected during the study were tabulated and analysed by an IBM 7044 computer. The distribution of inpatients and outpatients, their sex, and their age are shown in Table I.

TABLE I

Details of Patients Studied

\begin{tabular}{lccccccc}
\hline & Inpatients & Outpatients & Female & Male & Oldest & Youngest & $\begin{array}{c}\text { Mean } \\
\text { age }\end{array}$ \\
\hline Thiopentone & 43 & 57 & 25 & 75 & 83 & 9 & 50.960 \\
Diazepam & 39 & 61 & 28 & 72 & 83 & 9 & 51.340 \\
\hline
\end{tabular}

\section{RESULTS}

The amount of induction agent administered is shown in Table II. From the table it can be seen that the mean dose/weight ratio for diazepam is $0.33 \mathrm{mg} . / \mathrm{kg}$. and for thiopentone $4.1 \mathrm{mg}$. $/ \mathrm{kg}$. The mean time interval between the injection of thiopentone and the onset of sleep was 44.5 seconds, the longest interval being 150 seconds and the shortest 25 seconds. The corresponding figures for diazepam are 64,150 , and 25 seconds. It should be stated that patients induced with diazepam frequently did not go into a sound sleep, but rather were rendered sufficiently tranquil to accept nitrous oxide, oxygen, and halothane by face mask.

The mean concentration of halothane delivered by a Fluotec vaporizer during the first three minutes of anaesthesia was 1.5 per cent and 1.83 per cent for

TABLE II

DOSAGE ADMINISTERED

\begin{tabular}{lrrrrrrrr}
\hline & \multicolumn{3}{c}{ Total dose (mg.) } & & \multicolumn{3}{c}{ Dose (mg./kg.) } \\
\cline { 2 - 3 } & largest & smallest & mean & & largest & smallest & mean \\
\hline Thiopentone & 475 & 175 & 271 & & 7.250 & 2.365 & 4.1 \\
Diazepam & 35 & 11 & 22.415 & & .538 & .118 & .33 \\
\hline
\end{tabular}


thiopentone and diazepam respectively. The mean concentration of halothane required for maintenance of anaesthesia was .86 per cent with thiopentone compared to .74 per cent with diazepam.

Table III shows the clinical comparison of the effectiveness of the amount of induction agent used. Nineteen per cent of the inductions with diazepam were considered unsatisfactory; this was thought to be due to too small an initial dose. Twenty-seven per cent of the patients induced with thiopentone were given what was considered to be an insufficient induction dose; 21 per cent of the thiopentone group required additional drug.

TABLE III

INDUCTION DOSAGE

\begin{tabular}{lcccc}
\hline & Smooth & $\begin{array}{c}\text { Insuff. } \\
\text { dose }\end{array}$ & $\begin{array}{c}\text { Further } \\
\text { dose } \\
\text { reqd. }\end{array}$ & Overdose \\
\hline Thiopentone & 72 & 6 & 21 & 1 \\
Diazepam & 79 & 13 & 6 & 2 \\
\hline
\end{tabular}

Figure 2 illustrates changes in mean blood pressure one minute after administration of the induction agent. The mean blood pressure was derived from the formula ( $2 \mathrm{Ps}+3 \mathrm{Pd}) / 5$, where $\mathrm{Ps}$ and $\mathrm{Pd}$ are systolic and diastolic pressures. It

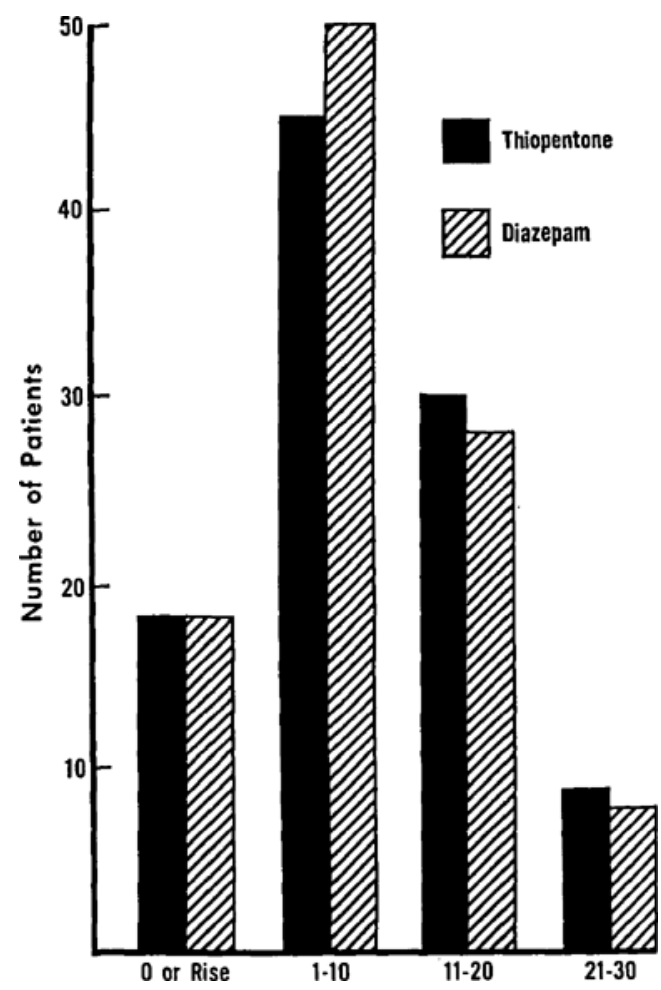

Figure 2. Blood pressure at one minute: per cent fall. 
is obvious that the mean blood pressure changes are similar with each agent. Seventeen per cent of each group exhibited a rise in mean arterial pressure, while 83 per cent showed a fall in mean blood pressure. In 44 per cent of the patients who received thiopentone, as compared to 48 per cent of those given diazepam, a 1 to 10 per cent fall in blood pressure occurred. Thirty-nine per cent of those given thiopentone had a fall of 11 per cent or greater, while 35 per cent of the diazepam group experienced a similar fall in blood pressure.

Figure 3 shows the mean blood pressure data three minutes after the administration of the induction agents. At this point the two groups are still remarkably similar. In 12 per cent of the thiopentone group, as compared to 9 per cent of

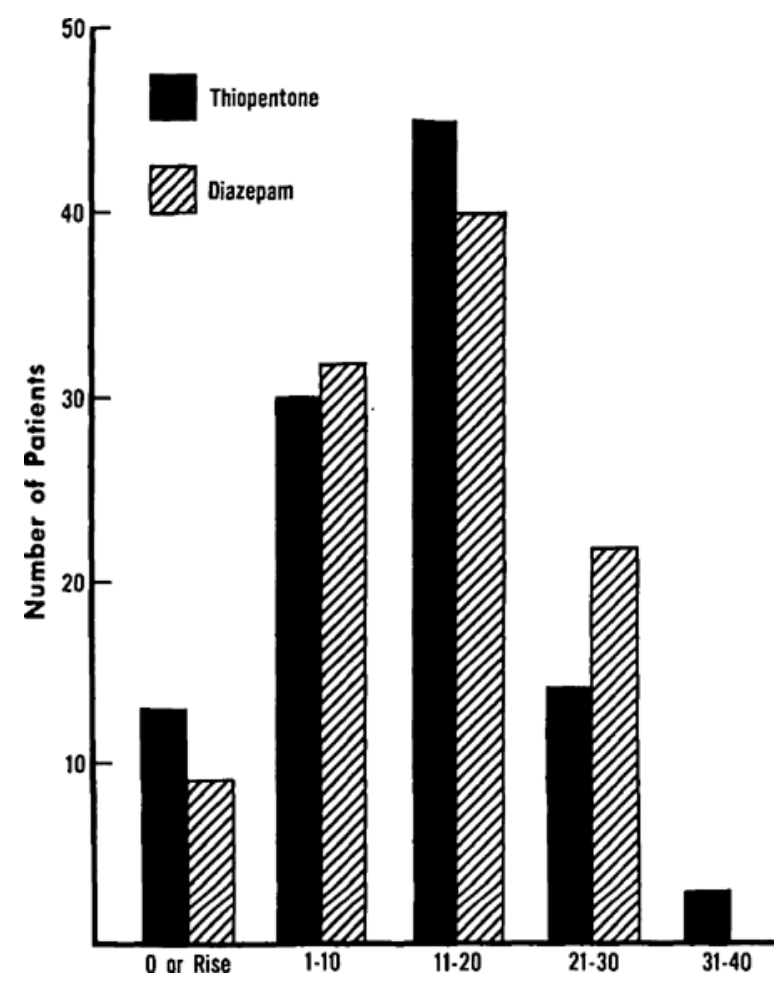
fall.

Figune 3. Blood pressure at three minutes: per cent

those receiving diazepam, mean blood pressure rose or remained stationary. Sixteen per cent of the patients receiving thiopentone, as compared to 22 per cent of those receiving diazepam, experienced a fall in mean blood pressure of 21 per cent or greater. Figure 4 shows alterations in pulse rate one minute after administration of the induction agent. In 31 per cent of the thiopentone group, as compared to 40 per cent of the diazepam group, there was no change or a fall in pulse rate. The two groups are comparable in that 50 per cent of the thiopentone group and 47 per cent of the diazepam group exhibited a rise in pulse rate of between 1 and 10 per cent. 


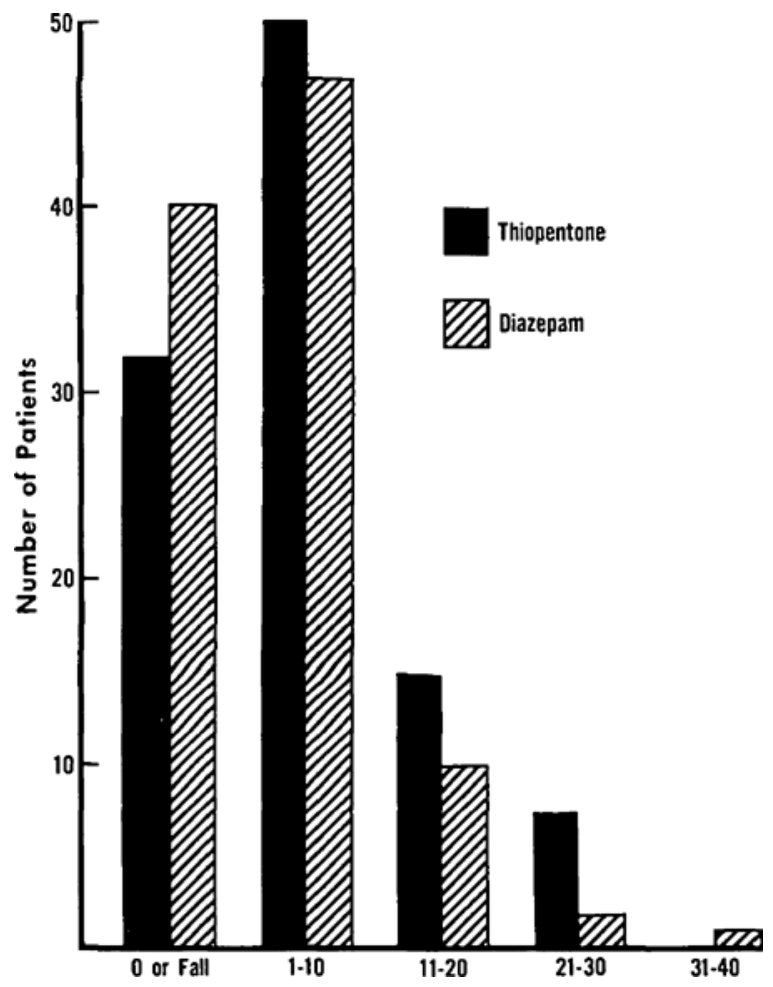

Figure 4. Pulse rate at one minute: per cent rise.

Observations of ventilatory patterns during induction revealed that 1 per cent of patients receiving thiopentone hyperventilated as compared to 2 per cent of the diazepam group. Thirty-two per cent of patients induced with thiopentone became apnoeic, the average duration of apnoea being 37.08 seconds. On the other hand, 20 per cent of patients induced with diazepam were apnoeic, the average duration being 29.67 seconds.

Troublesome peroperative complications encountered are listed in Table IV. Bronchospasm and vomiting were not encountered in this series.

TABLE IV

Peroperative Complications

\begin{tabular}{lcc}
\hline & Thiopentone (\%) & Diazepam (\%) \\
\hline Laryngospasm & 3 & 0 \\
Coughing & 17 & 9 \\
Hiccough & 4 & 6 \\
\hline
\end{tabular}

Time intervals for the return of pain perception and a satisfactory level of consciousness for both groups are shown in Table V. The results indicate that patients induced with thiopentone respond to painful stimuli and awaken more quickly than patients induced with diazepam. 
TABLE V

AnaEsthesia EMERGEnCE*

\begin{tabular}{|c|c|c|c|c|c|c|}
\hline & \multicolumn{3}{|c|}{ Thiopentone } & \multicolumn{3}{|c|}{ Diazepam } \\
\hline & shortest & longest & mean & shortest & longest & mean \\
\hline $\begin{array}{l}\text { Return to pain, halothane } \\
\text { discontinued }\end{array}$ & 1.000 & 36.000 & 8.610 & 1.000 & 85.000 & 14.380 \\
\hline $\begin{array}{l}\text { Return to pain, } \mathrm{N}_{2} \mathrm{O} \\
\text { discontinued }\end{array}$ & 0.000 & 36.000 & 7.312 & 0.000 & 85.000 & 11.235 \\
\hline $\begin{array}{l}\text { Return to consciousness, } \\
\text { halothane discontinued }\end{array}$ & 1.000 & 41.000 & 13.680 & 3.000 & 90.000 & 22.270 \\
\hline $\begin{array}{l}\text { Return to consciousness, } \\
\mathrm{N}_{2} \mathrm{O} \text { discontinued }\end{array}$ & 0.000 & 41.000 & 11.888 & 1.000 & 90.000 & 19.061 \\
\hline
\end{tabular}

*Measured in minutes.

Postoperative questioning of the 200 patients revealed that 99 patients in each group had a pleasant recall of anaesthesia. Twelve patients induced with thiopentone, as compared to two patients in the diazepam series, recalled a taste sensation following the administration of the induction agent.

Table VI enumerates the commonly encountered postanaesthetic complications. Twenty-three patients induced with thiopentone had some degree of postoperative dizziness, while fourteen patients in the diazepam group were similarly affected. Fifteen patients in the thiopentone group complained of postoperative

TABLE VI

Postoperative Complications

\begin{tabular}{|c|c|c|c|c|c|c|c|c|c|c|}
\hline & \multicolumn{2}{|c|}{ Drowsiness } & \multicolumn{2}{|c|}{ Headache } & \multicolumn{2}{|c|}{ Dizziness } & \multicolumn{2}{|c|}{ Nausea } & \multicolumn{2}{|c|}{ Vomiting } \\
\hline & thio. & diaz. & thio. & diaz. & thio. & diaz. & thio. & diaz. & thio. & diaz \\
\hline $\mathrm{Nil}$ & 24 & 28 & 18 & 78 & 77 & 86 & 85 & 94 & 98 & 97 \\
\hline $0-1 \mathrm{hr}$. & 30 & 13 & 3 & 10 & 15 & 8 & 7 & 2 & 1 & 1 \\
\hline $1-4$ & 32 & 30 & 10 & 5 & 3 & 3 & 4 & 2 & 1 & 2 \\
\hline $4-8$ & 9 & 22 & 4 & 2 & 2 & 0 & 2 & 1 & 0 & 0 \\
\hline $8-12$ & 2 & 2 & 1 & 2 & 0 & 0 & 0 & 0 & 0 & 0 \\
\hline $12-24$ & 2 & 4 & 3 & 1 & 2 & 2 & 1 & 0 & 0 & 0 \\
\hline Over 24 hrs. & 1 & 1 & 1 & 2 & 1 & 1 & 1 & 1 & 0 & 0 \\
\hline
\end{tabular}

drowsiness as compared to 72 per cent of the diazepam-induced patients. Postoperative drowsiness tended to last longer in the diazepam group. The incidence of postoperative headache was equal in both series, the diazepam-induced patients tending to have headaches of shorter duration. Postoperative vomiting was minimal in both groups. The increased incidence of prolonged drowsiness in the patients induced with diazepam has high statistical significance $(p<0.0025)$. Postoperative pain at the injection site was determined in each group. Six per cent of the paitents induced with thiopentone had discomfort, while 8 per cent in the diazepam series had similar complaints. Two of the patients in the latter group had phlebitis. 
Table VII compares the two groups in their return to normal activity. From this table it is evident that the two groups are comparable except for the day of operation, when a slightly higher percentage of patients induced with diazepam required bed rest.

TABLE VII

Postoperative Activity (Number of Patients)

\begin{tabular}{lcc}
\hline \hline & Thiopentone & Diazepam \\
\hline Bedrest day of operation & 12 & 18 \\
Bedrest day 1st p.o. day & 3 & 5 \\
Bedrest after 1st p.o. day & 1 & 1 \\
Normal activity on return to ward or home & 33 & 29 \\
Normal activity 1st p.o. day & 51 & 47 \\
\hline
\end{tabular}

Table VIII compares pre- and postoperative amnesia in the two groups. Amnesia for immediate preoperative events occurred in only a few patients in each group. Postoperatively, the two groups had a similar incidence of amnesia; however, the amnesic period was longer in the patients induced with diazepam $(p=0.01)$.

TABLE VIII

\begin{tabular}{lcc}
\multicolumn{3}{c}{ Amesia Rating } \\
\hline & Thiopentone & Diazepam \\
\hline Preoperative amnesia & 99 & 94 \\
nil & 0 & 4 \\
$0-15$ mins. & 1 & 1 \\
15-30 mins. & 0 & 0 \\
$20-60$ mins. & 0 & 1 \\
$1-4$ hrs. & & \\
Postoperative amnesia & 5 & 6 \\
nil & 80 & 46 \\
$0-15$ mins. & 14 & 29 \\
$15-30$ mins. & 1 & 8 \\
$30-60$ mins & 0 & 3 \\
$1-2$ hrs. & 0 & 3 \\
$2-3$ hrs. & 0 & 1 \\
$3-4$ hrs. & 0 & 2 \\
$4-12$ hrs. & 0 & \\
more than 12 hrs. & & \\
\hline
\end{tabular}

\section{Discussion}

The experience gained in the use of diazepam revealed that $0.3 \mathrm{mg} . / \mathrm{kg}$. is an adequate dose in 79 per cent of patients. The 19 per cent incidence of inadequate dosage in the diazepam series indicates that an appreciable number of patients premedicated with atropine alone will require a higher dose per kilogram of body weight. The majority of patients in this latter group were, however, rendered sufficiently tranquil to allow an easy induction with nitrous oxide, oxygen, and halothane. We were unable to predict clinically which patients might deviate from the estimated dose of $0.3 \mathrm{mg} . / \mathrm{kg}$. We were often deficient in our dosage in 
elderly subjects in whom we anticipated a low mg. $/ \mathrm{kg}$. requirement. The mean dose of thiopentone required is comparable to that reported in an earlier study. ${ }^{6}$

The mean time between injection of diazepam and the onset of sleep was approximately 30 per cent longer than in the patients induced with thiopentone. A higher mean concentration of halothane was required during the first three minutes to achieve satisfactory operating conditions in patients induced with diazepam. The amount of halothane required for the maintenance of anaesthesia in patients induced with diazepam was lower than in the thiopentone series. This is probably due to a difference in the rate of distribution of the two drugs between blood and various tissue compartments of the body.

The similarity of the changes in the mean arterial blood pressure at one and three minutes is striking. Our observation that mean blood pressure decreased 10 per cent or more in 35 per cent of patients receiving diazepam intravenously is in disagreement with other reports..$^{4,7}$ However, Prensky et al..$^{5}$ encountered one cardiac arrest and two cases of transient hypotension in patients with acute cerebral disorders in their series of thirty patients. We can reasonably conclude that in patients receiving no other medication except intravenous atropine just prior to diazepam, a fall in blood pressure comparable to thiopentone does occur within the first minute. This may be due to a similar myocardial depressant action of the two drugs. At three minutes, the effects of halothane make conclusions regarding the depressant effects of either induction agent unreliable. Therefore, diazepam or thiopentone must be used judiciously if hypotension is to be avoided.

The initial rise in pulse rate in the majority of patients in both groups can be assumed to be due to compensatory cardiovascular reflexes, caused by the depression of mean blood pressure within one minute after injection of the drug.

Apnoea was noted in both groups immediately after injection. However, 12 per cent more patients were apnoeic in the thiopentone group, with a longer duration of apnoea. In our experience, it would seem that although this difference is real on paper, it was clinically inconsequential in the conduct of anaesthesia. Only half as many of the patients induced with diazepam coughed on induction of anaesthesia. This may indicate that diazepam depresses the respiratory reflexes.

Patients induced with diazepam were much slower in responding to a pain stimulus and in returning to consciousness than patients induced with thiopentone. However, both groups were comparable in their time of return to normal activity. This similarity may have been due to the inhalation agents which all patients received, the return to activity being influenced by nitrous oxide and halothane rather than by the induction agents.

Postoperatively, the thiopentone group exhibited a greater incidence of dizziness and nausea, while the diazepam group had a higher occurrence of amnesia. It is noteworthy that the majority of the patients induced with thiopentone (85\%) were free of amnesia within 15 minutes of the completion of the operation as compared to only 52 per cent of those induced with diazepam. By thirty minutes only one of the thiopentone patients was amnesic as compared to 19 per cent of the diazepam group. Eleven per cent of the patients in the diazepam series had postoperative amnesia lasting more than one hour. The tendency towards a 
longer period of amnesia in the diazepam patients may have been a factor in the decreased number of postoperative complaints voiced by this group.

Analysis of the patients induced with diluted diazepam 0.1 per cent showed no statistically significant difference in the per- and postoperative complications as compared with the patients induced with 0.5 per cent diazepam.

\section{SUMMARY}

Experience with 200 cases has been presented, in which 2.5 per cent thiopentone was used as the induction agent in 100 cases, 0.1 per cent diazepam in fifty cases, and 0.5 per cent diazepam in the remaining fifty. Patients were compared during the induction, peroperative, emergence, and postoperative periods. Patients induced with diazepam were slower in going to sleep than those induced with thiopentone. In some instances patients induced with diazepam did not lose consciousness completely; they were, however, extremely co-operative, and induction of anaesthesia was easily completed with nitrous oxide, oxygen, and halothane. Cardiovascular effects of the two agents are comparable when used in the manner described above. Effects on the respiratory system were less pronounced with diazepam. Patients induced with diazepam were more drowsy and tended to have a longer period of amnesia postoperatively than those in the thiopentone group. Both groups, however, were comparable in their return to normal activity.

\section{RÉSUMÉ}

Nous avons présenté les résultats de nos études faites sur deux cents malades chez qui nous avons varié l'agent d'induction de la façon suivante: chez cent malades nous avons employé le thiopentane à 2.5 pour cent, chez cinquante malades, le diazepam 0.1 pour cent et chez les autres, le diazepam à 0.5 pour cent. Nous avons comparé ces malades au cours de différentes périodes: l'induction, l'opération, le réveil et les suites opératoires. Chez les malades soumis au diazépam, l'induction a été plus lente que chez malades soumis au thiopentone. Certains malades soumis au diazepam n'ont jamais perdu connaissance complètement. En dépuit de cela, ils ont collaboré entièrement et nous avons pu passer à l'induction de l'anesthésie au protoxyde d'azote oxygène et halothane sans difficulté. S'ils sont utilisés de la façon décrite ci-contre, les effets cardiovasculaires des deux agents sont comparables. Les échos sur le système respiratoire ont été moins marqués avec l'usage du diazépam. Les malades soumis au diazépam sont demeurés plus somnolents et amnésiques durant une plus longue période après l'opération que ceux qui avaient reçu du thiopentone. En résumé, en ce qui conceme le retour à l'activité, les malades des deux groupes sont tout à fait comparables.

\section{ACKNOWLEDGMENTS}

We wish to thank Hoffmann-La Roche Company for its assistance in carrying out this project. 


\section{REFERENCES}

1. Brandt, A. L. \& Oakes, F. D. Preanaesthesia Medication: Double-blind Study of a New Drug, Diazepam. Anesth. \& Analg. 44: 1 (1965).

2. Rogers, W. K.; Waterman, D. H.; Domm, S. E.; \& Suzay, A. Efficacy of a New Psychotropic Drug in Bronchoscopy. Dis. Chest. 47: 280 (1965).

3. Cormier, A.; Goyette, M.; Kefiri-Szanto, M.; \& Rheautr, J. A Comparison of the Action of Meperidine and Diazepam in Anaesthetic Premedication. Canad. Anaesth. Soc. J. 13: 368 (1966).

4. MCClish, ANDrÉ. Diazepam as an Intravenous Induction Agent for General Anaesthesia. Canad. Anaesth. Soc. J. 13: 562 (1966).

5. Prensky, arthur, L.; Raff, Martin C.; Moore, Michael J.; \& Schwab, Robert S. Intravenous Diazepam in the Treatment of Prolonged Seizure Activity. New England J. Med. 276: 779 (1967).

6. Wynands, J. E. \& Fox, G. S. A Clinical Comparison of Propanidid and Thiopentone as Induction Agents to General Anaesthesia. Canad. Anaesth. Soc. J. 13: 505 (1966).

7. Trcktin, H. E. \& TrujILlo, N. P. Evaluation of Diazepam for Pre-endoscopy Medication. Am. J. Digest. Dis. 10: 979 (1965). 